\title{
CIRCUMFERENTIAL PROXIMAL FEMORAL ALLOGRAFTS IN TOTAL HIP ARTHROPLASTY REVISION SURGERY
}

Bruno Dutra Roos ${ }^{1}$, Milton Valdomiro Roos ${ }^{2}$, Antero Camisa Júnior ${ }^{1}$, Henrique Bonotto Lampert ${ }^{3}$, Matheus Luis da Silva ${ }^{3}$

\section{ABSTRACT}

Objective: To evaluate the clinical and radiographic results from patients who underwent femoral reconstruction secondary to loosening of total hip arthroplasty, using circumferential proximal femoral allografts and cemented implants. Methods: A retrospective study was conducted on 32 patients (33 hips) who underwent femoral reconstruction secondary to loosening of total hip arthroplasty, using circumferential proximal femoral allografts and cemented implants. Among these patients, 28 (29 hips) fulfilled all the requirements for this study. The mean follow-up was five years and two months. The clinical evaluation was done in accordance with the Harris Hip Score. Radiographically, the patients were assessed regarding reabsorption and consolidation of the allograft, migration of the greater trochanter, stability of the femoral component and heterotypic calcification. Results: The average preoperative Harris Hip Score was 32 points. At the last postoperative follow-up, the average score was 82 points. Allograft resorption of some degree was seen in nine hips (31\%). Regarding consolidation, 24 cases $(82.8 \%)$ showed full consolidation, three $(10.3 \%)$ showed partial consolidation and two (6.9\%) showed pseudarthrosis. All femoral components were stable. According to the criteria established, 27 cases (93.1\%) were considered to be successful reconstructions after a mean follow-up of five years and two months. Conclusion: From the results obtained, it was concluded that use of circumferential proximal femoral allografts in selected cases of femoral reconstruction secondary to loosening of arthroplasty presented a high survival rate from the reconstruction over an average follow-up of five years and two months.

Keywords - Arthroplasty, Replacement, Hip/methods; Femur/surgery; Homologous Transplant/adverse effects; Prosthesis Failure.

\section{INTRODUCTION}

Implant loosening after total hip arthroplasty can lead to extensive femoral osteolysis in the long term. In such cases, the use of conventional revision techniques does not produce satisfactory results ${ }^{(1-3)}$.

There are numerous methods of surgical treatment described in the literature for overcoming this problem, but there is still no consensus on the best technique to use. Circumferential allograft of the proximal or distal femur, fragmented bone graft combined with surgical meshes, structural cortical bone graft, endoprostheses, and distal fixation of femoral stems are some of the alternatives $^{(1-3)}$.
The use of a circumferential femoral allograft allows for reconstruction of the defects over an extensive area, correcting the hip abductor mechanism and length discrepancy in of the $\operatorname{limb}^{(1,2)}$. It also presents osteoconductive potential, in that it allows for gradual replacement by host bone, with consequent replacement of bone stock, providing favorable bed for future revisions if needed.

The purpose of this article is to evaluate the clinical and radiographic results, and the survival of femoral reconstruction secondary to loosening of total hip arthroplasty with use of circumferential proximal femoral allograft and cemented implant.

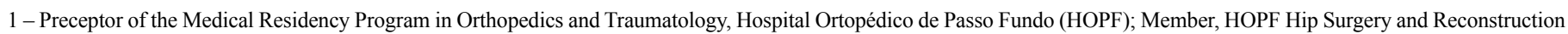
Group, Passo Fundo, RS, Brazil.

2 - Head, HOPF Medical Residency Program in Orthopedics and Traumatology ; Member, HOPF Hip Surgery and Reconstruction Group, Passo Fundo, RS, Brazil.

3 - Third-Year Resident, HOPF Orthopedics and Traumatology Training Program, Passo Fundo, RS, Brazil.

Study conducted at the Hospital Ortopédico de Passo Fundo, School of Medicine, Universidade de Passo Fundo - Passo Fundo, RS

Correspondence: Av. Sete de Setembro, 817, Centro - 99010-121 - Passo Fundo, RS, Brazil. Email: brunodroos@gmail.com

Received for publication: 2/12/2012, accepted for publication: 4/12/2012.
}

The authors declare that there was no conflict of interest in conducting this work 


\section{MATERIALS AND METHODS}

We conducted a retrospective study of 32 patients (33 hips) who underwent femoral reconstruction secondary to loosening of total hip arthroplasty with use of circumferential proximal femoral allograft and cemented implant, from March 1988 to February 2008. All reconstructions were performed by the same surgeon of the clinic (MVR). This study was approved by the Research Ethics Committee of the Universidade de Passo Fundo.

The study included patients with one previous arthroplasty or more, which underwent femoral reconstruction using (non-irradiated) circumferential proximal femoral allograft in combination with cemented implant, and had a minimum follow-up period of one year.

Exclusion criteria were loss to follow-up (two cases) and death before the minimum follow-up (two cases).

According to the criteria, 28 patients (29 hips) met all requirements for this study, including 23 female and five male patients. Of these, 27 patients underwent surgical treatment for aseptic loosening of arthroplasty and two for infection (septic loosening, with reconstruction in two stages). The right side was predominant in 21 hips.

The mean patient age at surgery was 61.4 years $(28$ to 85 years). Mean follow-up was 5.15 years (61.8 months), and the longest follow-up period was 20 years and six months. The average length of the allograft was $13.4 \mathrm{~cm}$ ( 8 to $20 \mathrm{~cm}$ ), measurement performed from the apex of the greater trochanter.

The methods used for fixation of the allograft were structural cortical graft combined with cerclage in 12 cases, eight cases with plate and screws, three cases with cerclage alone, three cases with plate and screws plus cerclage, two cases with plate and screws combined with structural graft and cerclages, and one case with structural cortical graft and screws.

Patients were clinically classified preoperatively and postoperatively by the Harris Hip Score ${ }^{(4)}$. Clinical success was defined as an increase of 20 points in the Harris Hip Score ${ }^{(4)}$ postoperatively compared to the preoperative score, stable implant, and no need for further surgery at the time of revision ${ }^{(3)}$.

Bone defects were determined according to the D'Antonio classification adopted by the American Academy of Orthopaedic Surgeons (AAOS) ${ }^{(5)}$.

The presence of endosteal and periosteal resorption of the graft were evaluated in the femoral areas described by Gruen et $\mathrm{al}^{(6)}$. Zones one and four were excluded due to the absence of the greater trochanter (zone one) and the graft-host junction (zone four) (3). Mild resorption was defined by less than $1 \mathrm{~cm}$ partial absorption of cortical thickness; moderate resorption as more than $1 \mathrm{~cm}$ partial absorption of cortical thickness; and severe resorption as absorption of the entire cortical thickness for any length ${ }^{(3)}$.

Allograft consolidation was assessed in late postoperative radiographs. Cases where there was no radiolucency line at the graft-host bone interface were considered consolidated, cases where there was partial radiolucency line were considered partial consolidation, and line radiolucency on the entire interface were considered fibrous union or pseudarthrosis ${ }^{(3)}$.

In radiographs taken in the immediate and late postoperative period the migration of the host greater trochanter was compared. Migration greater than $1 \mathrm{~cm}$ was considered trochanteric pseudarthrosis ${ }^{(3)}$.

The femoral implant stability was evaluated for the presence of radiolucent lines in the cement-bone interface and their migration. Component loosening was defined as evidence of vertical migration greater than $3 \mathrm{~mm}$ or cement fracture ${ }^{(3)}$.

The presence of heterotopic calcification of the hip was classified according to Brooker et $\mathrm{al}^{(7)}$.

To avoid inter- and intraobserver errors, measurements were accompanied by two surgeons from the Hip Surgery and Reconstruction Group (BDR and ACJr). In case of disagreement, a new assessment was performed by a third surgeon (MVR), proceeding through measurement consensus.

Statistical analysis was performed to compare preoperative and postoperative measurements of the Harris Hip Score ${ }^{(4)}$, using the Wilcoxon test.

A Kaplan-Meier curve was performed for cumulative survival analysis by month of reconstruction. Allograft failure was defined as the need to remove the femoral implant or graft, or severe cortical resorption ${ }^{(3)}$.

\section{Surgical technique}

To choose the most adequate allografts that best suits the patient's femur, each case is assessed preoperatively and the extent of femoral defect is measured.

We used an anterolateral surgical approach combined with osteotomy of the greater trochanter in all cases. The surgical technique used is similar to that 
described previously by Blackley et $\mathrm{al}^{(3)}$. Currently, we prefer circumferential femoral allograft telescoping method inside the host bone whenever possible due to the great stability of the reconstruction (Figure 1). If necessary, we use a structural cortical graft and ties with cerclages as accessory elements for fixation.

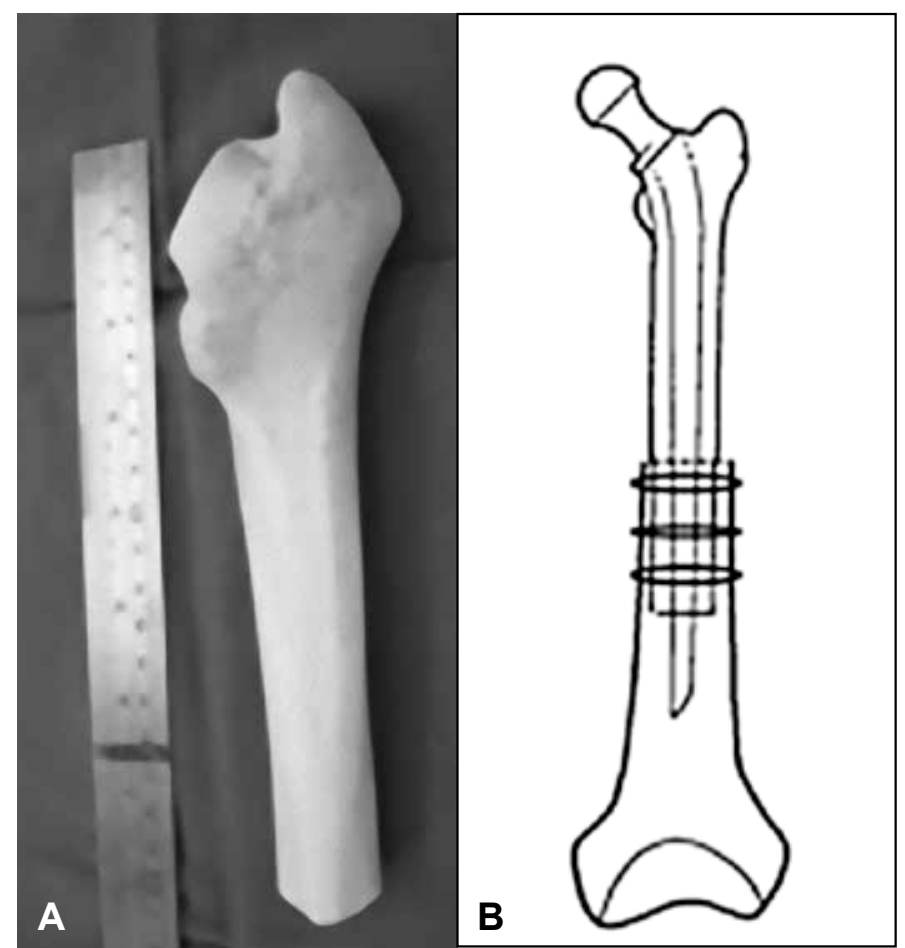

Figure 1 - (A) Circumferential proximal femoral allograft. (B) Characteristics of the telescoping method for stabilizing the allograft. Source: HO/Passo Fundo, RS.

\section{Postoperative management}

Patients are kept on bed rest for approximately 48 hours (varying according to the transoperative circumstances) and are thereafter allowed to be in a sitting position (outside the bed). Mechanical thromboembolic prophylaxis was used in the immediate postoperative period, antiplatelets for 30 days and intravenous antibiotic therapy with vancomycin for 10 days. Moreover, one gram of vancomycin was added to each dose of bone cement used. Radiographic evaluation is performed nine weeks after surgery. At that time, full support is allowed with a crutch as a balance aid (Figure 2).

\section{RESULTS}

The clinical classification of patients according to the Harris Hip Score ${ }^{(4)}$ showed a preoperative mean of 32 points (20 to 46 points). In the late postoperative

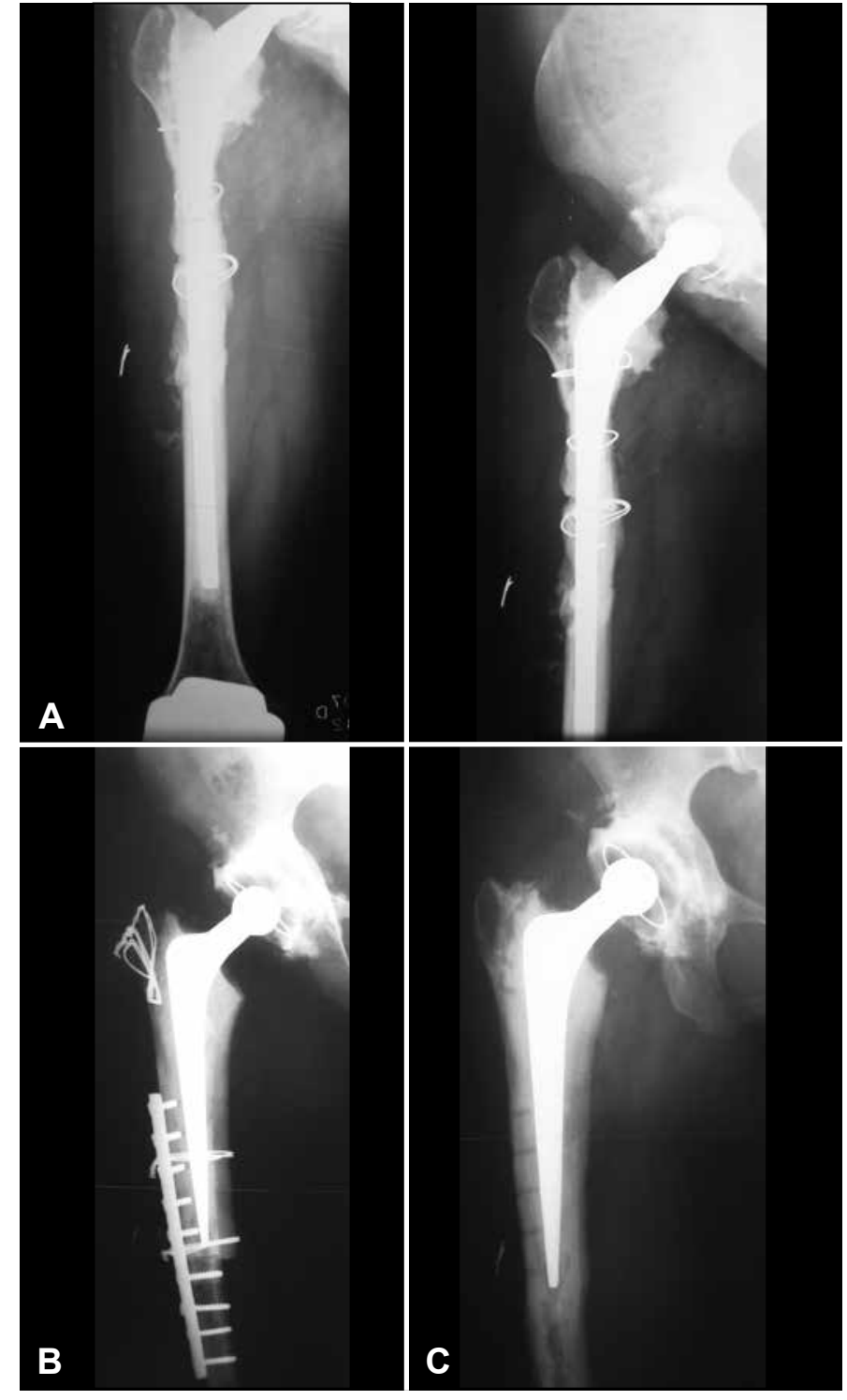

Figure 2 - (A) Patient, 26 years old, with juvenile rheumatoid arthritis with multiple previous surgeries. Preoperative radiograph presenting combined femoral defect. (B) Immediate postoperative radiograph, showing femoral reconstruction with use of circumferential proximal femoral allograft and cemented implant. (C) Radiograph six years postoperatively, after the withdrawal of synthesis, showing consolidated graft. Patient ambulating without pain. Source: HO/Passo Fundo, RS.

period, the average was 82 points (59 to 98 points). The evaluation of the results showed a statistically significant difference $(\mathrm{p}<0.05)$ between the pre- and postoperative measurements.

According to the AAOS classification ${ }^{(5)}$, of the 29 hips evaluated, $25(86.2 \%)$ femoral defects were considered combined, and four (13.8\%) segmental. Regarding the location of the defects, two cases $(6.9 \%)$ were classified as level I (proximal to the lower region of the lesser trochanter) and the remaining level II (up to $10 \mathrm{~cm}$ distal to the lower region of the lesser trochanter). All patients had grade III bone loss 
(absence of host bone-implant contact). Considering allograft resorption, there were three cases $(10.3 \%)$ of mild resorption, five $(17.2 \%)$ had moderate resorption, and one (3.4\%) had severe resorption (Figure 3). Zones two and six defined by Gruen et al. ${ }^{(6)}$ were the most frequently affected, and in two cases $(6.9 \%)$ they were simultaneously impaired. There was no relationship between the duration of follow-up and degree of resorption.

With regard to the consolidation of the allograft, 24 cases $(82.8 \%)$ of consolidation were observed, three cases of partial consolidation (10.3\%), and two cases $(6.9 \%)$ with fibrous union or pseudarthrosis (unconsolidated) (Figure 4). Of the patients without evidence of consolidation, one was asymptomatic at 12 months of follow-up. The other underwent a new surgical treatment of allograft fixation with plate and screws combined with structural cortical graft at 12 months follow-up, and is currently symptomatic again with no evidence of consolidation for the circumferential graft at 31 months follow-up.

Evaluation of the migration of the greater trochan-

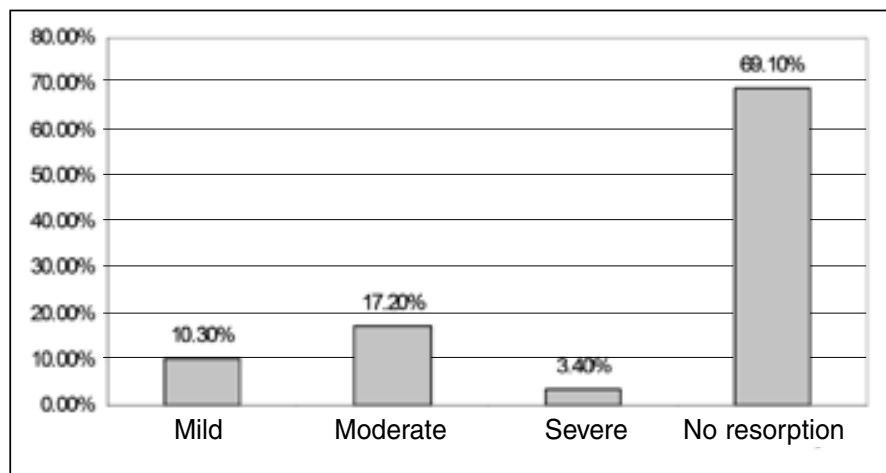

Figure 3 - Characteristics of patients according to the severity of allograft absorption.

Source: HO/Passo Fundo, RS.

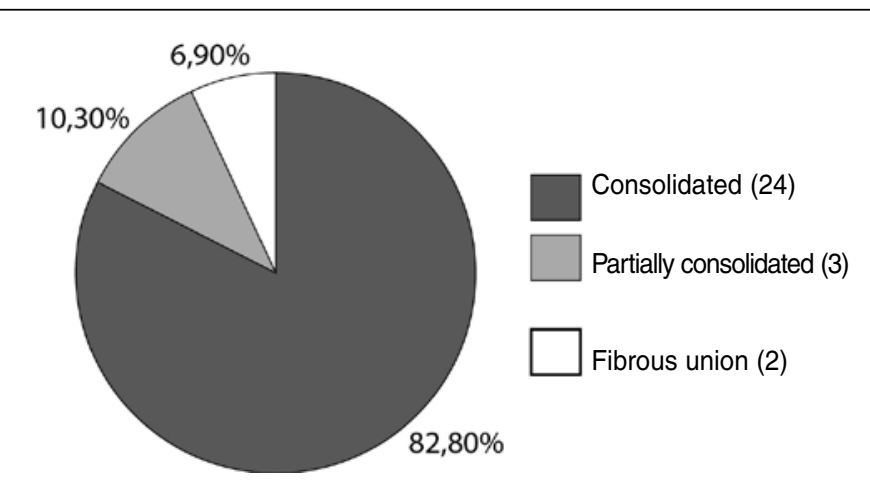

Figure 4 - Characteristics of patients regarding the consolidation of the allograft. Source: HO/Passo Fundo, RS. ter showed one case $(3.4 \%)$ with migration greater than $1 \mathrm{~cm}$ (trochanteric pseudarthrosis). In two hips $(6.9 \%)$ the measurement could not be performed due to the absence of the host greater trochanter.

Vertical migration of the femoral implant greater than $3 \mathrm{~mm}$ or cement fracture was not observed, indicating component stability.

The Brooker et al. classification ${ }^{(7)}$ assessing the presence of heterotopic hip calcification considered 23 patients $(79.3 \%)$ to have grade 0 , five $(17.2 \%)$ to have grade I, and one (3.4\%) to have grade II.

Thus, according to the definition proposed clinical success was obtained in 27 cases (93.1\%). Of the two unsuccessful cases, one patient presented a late infection (seven years and two months of followup) and the other presented pseudarthrosis requiring further intervention.

According to the criteria established for allograft failure, we considered 27 cases (93.1\%) to have had successful reconstruction in a mean follow-up period of five years and two months. In one of the cases of failure, the presence of severe resorption was revealed in zone two of Gruen et $\mathrm{al}^{(6)}$ (at 19 years and six months of follow-up). In the other, it was necessary to remove the femoral implant due to infection (the allograft remained).

The most frequent complications were: six cases (20.7\%) of prosthetic dislocation, three cases $(10.3 \%)$ of periprosthetic fracture, two cases (6.9\%) of fibrous union or pseudarthrosis, one case $(3.4 \%)$ of sciatic nerve lesion (with full recovery) and one case (3.4\%) of infection (which occurred late at seven years and two months of follow-up) (Table 1).

In survival analysis, estimated at 20 years, a $83.3 \%$ chance of success was encountered at 86 months $(95 \%$ CI [69.63; $97.03 \%])$, and $41.67 \%$ at 234 months $(95 \%$ CI $[23.77 ; 59.57 \%]$ ) (Figure 5).

Table 1 - Distribution of postoperative complications with their percentages.

\begin{tabular}{c|c}
\hline Complications & Percentage \\
\hline Periprosthetic dislocation & $20.70 \%$ \\
\hline Periprosthetic fracture & $10.30 \%$ \\
\hline Pseudarthrosis & $6.90 \%$ \\
\hline Sciatic nerve injury & $3.40 \%$ \\
\hline Infection & $3.40 \%$ \\
\hline No complications & $55.30 \%$ \\
\hline
\end{tabular}

Source: HO/Passo Fundo, RS. 


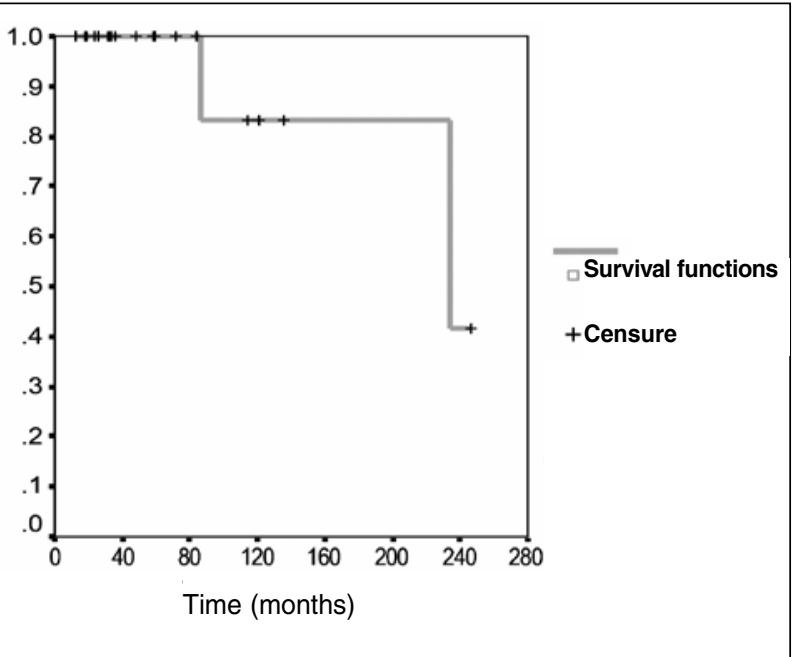

Figure 5 - Reconstruction survival curve.

Source: HO/Passo Fundo, RS.

\section{DISCUSSION}

There are numerous methods of femoral reconstruction for total hip arthroplasty revision reported in the literature. Among them, the use of circumferential allograft of the proximal or distal femur, fragmented bone graft with or without surgical meshes, structural cortical bone graft, endoprostheses and distal fixation of femoral stems ${ }^{(1-3)}$. However, few options can be applied in cases of extensive circumferential bone defects (greater than $5 \mathrm{~cm})^{(3)}$. In these patients, the most commonly used techniques are the endoprostheses and circumferential femoral allografts.

The use of endoprostheses has complications such as instability due to poor fixation of soft tissue, fracture due to implant stress, and early loosening. Nor do they help in restoring bone stock ${ }^{(1-3,8,9)}$.

The use of circumferential femoral allografts remains controversial in the literature. Many of the publications show a small number of patients and various surgical techniques and types of allografts being used, as well as different implants. In addition, few authors report medium to long-term follow-ups ${ }^{(1-3,8,10-15)}$. In the national literature, to our knowledge, there are no articles assessing this type of femoral reconstruction technique.

Blackley et $\mathrm{al}^{(3)}$ evaluated 63 hips submitted to femoral reconstruction using circumferential femoral allograft in combination with cemented implant and observed $86 \%$ reconstruction survival at a mean follow-up of 10 years. There were 13 complications ( $21 \%$ of patients) requiring further surgery.

Haddad et $\mathrm{al}^{(10)}$ reported $89 \%$ survival of hip reconstruction with use of circumferential proximal femoral allograft in 55 hips evaluated, with a mean follow-up period of 8.8 years. There was a large number of complications, among them 22 trochanteric pseudarthrosis and six cases of instability. The article presented a combined analysis of cases of cemented and cementless implants.

The literature describes a large number of complications related to this type of reconstruction technique $^{(1-3,8,10-11,15)}$. Those that most frequently require a new surgical procedure are infection, pseudarthrosis, allograft fracture, and instability. Furthermore, the use of homologous graft presents a potential risk of disease transmission, which is minimal with current methods of harvesting, processing, and storing of musculoskeletal tissues ${ }^{(16)}$.

The incidence of infection, the most feared complication, can range from $3^{(15)}$ to $20 \%{ }^{(17)}$ of cases. The main factors are related to the duration of the procedure, the degree of tissue damage at the time of the intervention and the amount of blood loss ${ }^{(2,11)}$.

Pseudarthrosis at the graft-host bone junction may occur in $3.5^{(15)}$ to $23 \%^{(13)}$ of reconstructions. This outcome can be avoided by providing the largest possible contact between the graft and host bone (via osteotomies that increase the contact surface and avoid the presence of localized bone cement), rigid internal fixation with the use of structural cortical graft in combination with cerclage, the use of available autograft during surgery (femoral or acetabular) to fill in the interface, and maintenance of the insertion of soft tissue in the remaining bone (which should be fixed around the femoral allograft) $)^{(3)}$.

Allograft fracture is a complication described between $0^{(3)}$ and $16.5 \%{ }^{(12)}$ of series. According to the literature, one can reduce its incidence with the use of femoral implants beyond the graft-host bone junction (reaching the diaphysis of the remaining femur) and avoiding the presence of screws or plates in the allograft (which may cause it to weaken) $^{(3)}$.

Another potential complication is instability, which in reconstructive surgery of the hip is mainly related to impairment of the abductor mechanism (which is often severely affected) and limb length discrepancy. 
Its incidence may range from $6^{(3)}$ to $22.7 \%{ }^{(17)}$ of cases. Some authors suggest the use of constricted acetabular components when stability is poor ${ }^{(18-20)}$.

In this study, the use of circumferential proximal femoral allograft showed satisfactory clinical results and $93.1 \%$ survival of reconstruction in an average follow-up of five years and two months. The most frequent complication was prosthetic dislocation $(20.7 \%)$, which was also found in studies by other authors ${ }^{(3,16)}$.

One limitation of this study is the small number of patients, but this type of femoral reconstruction is considered exceptional. Another limitation is the use of dif- ferent methods of fixation in circumferential allografts, which may be reflected in non-homogeneous results.

\section{CONCLUSION}

Based on these results, we conclude that the use of circumferential proximal femoral allograft in femoral reconstruction secondary to loosening of hip arthroplasty has a high survival rate and satisfactory clinical results in an average follow-up of five years and two months in selected patients. There is a large number of associated complications, which is inherent to the severity and complexity of cases.

\section{REFERENCES}

1. Haddad FS, Garbuz DS, Masri BA, Duncan CP. Structural proximal femoral allografts for failed total hip replacements: a minimum review of five years. $J$ Bone Joint Surg Br. 2000;82(6):830-6.

2. Graham NM, Stockley I. The use of structural proximal femoral allografts in complex revision hip arthroplasty. J Bone Joint Surg Br. 2004;86(3):337-43.

3. Blackley HR, Davis AM, Hutchison CR, Gross AE. Proximal femoral allografts for reconstruction of bone stock in revision arthroplasty of the hip. A nine to fifteen-year follow-up. J Bone Joint Surg Am. 2001;83(3):346-54. 7.

4. Harris WH. Traumatic arthritis of the hip after dislocation and acetabular fractures: treatment by mold arthroplasty. An end-result study using a new method of result evaluation. J Bone Joint Surg Am. 1969;51(4):737-55.

5. D'Antonio J, McCarthy JC, Bargar WL, Borden LS, Cappelo WN, Collis DK, et al. Classification of femoral abnormalities in total hip arthroplasty. Clin Orthop Relat Res. 1993;(296):133-9.

6. Gruen TA, McNeice GM, Amstutz HC. "Modes of failure" of cemented stem-type femoral components: a radiographic analysis of loosening. Clin Orthop Relat Res. 1979;(141):17-27.

7. Brooker AF, Bowerman JW, Robinson RA, Riley LH Jr. Ectopic ossification following total hip replacement. Incidence and a method of classification. J Boné Joint Surg Am. 1973;55(8):1629-32.

8. Duncan CP, Masri BA. Fractures of the femur after hip replacement. Instr Course Lect. 1995;44:293-304.

9. Malkani AL, Sim FH, Chao EY. Custom-made segmental femoral replacement prosthesis in revision total hip arthroplasty. Orthop Clin North Am. 1993;24(4):727-33.

10. Haddad FS, SpangehI MJ, Masri BA, Garbuz DS, Duncan CP. Circumferential allograft replacement of the proximal femur. A critical analysis. Clin Orthop Relat Res. 2000;(371):98-107.

11. Martin WR, Sutherland CJ. Complications of proximal femoral allografts in revision total hip arthroplasty. Clin Orthop Relat Res. 1993;(295):161-7.

12. Mankin HJ, Doppelt S, Tomford W. Clinical experience with allograft implantation. The first ten years. Clin Orthop Relat Res. 1983;(174):69-86.

13. Gitelis S, Piasecki P. Allograft prosthetic composite arthroplasty for osteosarcoma and other aggressive bone tumors. Clin Orthop Relat Res. 1991;(270):197-201.

14. Wang JW, Wang CJ. Proximal femoral allografts for bone deficiencies in revision hip arthroplasty: a medium-term follow-up study. J Arthroplasty. 2004;19(7):845-52.

15. Gross AE, Hutchison CR. Proximal femoral allografts for reconstruction of bone stock in revision arthroplasty of the hip. Orthop Clin North Am. 1998;29(2):313-7.

16. Roos MV, Camisa Jr A, Michelin AF. Procedimentos de um banco de ossos e aplicabilidade dos enxertos por ele proporcionados. Acta Ortop Bras. 2000;8(3):122-7.

17. Head WC, Hillyard JM, Emerson RH Jr, Peters PC Jr. Proximal femoral allografts in revision total hip arthroplasty. Semin Arthroplasty. 1993;4(2):92-8.

18. Guyen O, Lewallen DG, Cabanela ME. Modes of failure of Osteonics constrained tripolar implants: a retrospective analysis of forty-three failed implants. J Bone Joint Surg Am. 2008;90(7):1553-60.

19. Anderson MJ, Murray WR, Skinner HB. Constrained acetabular components. J Arthroplasty. 1994;9(1):17-23.

20. Shrader MW, Parvizi J, Lewallen DG. The use of a constrained acetabular component to treat instability after total hip arthroplasty. J Bone Joint Surg Am. 2003;85-(11):2179-83. 